\title{
PENGARUH TEKANAN UDARA TERHADAP TEMPERATUR PEMBAKARAN OLI BEKAS PADA KOMPOR
}

\author{
Gilang Wahyu Ramadhan ${ }^{1}$, Basyirun ${ }^{2}$ \\ ${ }^{1,2}$ Pendidikan Teknik Mesin, Fakultas Teknik, Universitas Negeri Semarang \\ Email: konamigilang@gmail.com
}

\begin{abstract}
Used oil is a waste, and optimization is needed to use it as a fuel properly. In the combustion of used oil, air pressure is very influential in achieving optimal temperature. The air pressure affects the pressure of the incoming air. Other than temperature, air pressure affects and determines the inflow air density. The research uses an experimental method. This study concludes that air pressure affects the temperature of used oil combustion. The higher the air pressure, the more optimum the combustion temperature. A pressure of 2.5 bar yields in maximum temperature of $994.5^{\circ} \mathrm{C}$ and a combustion time of 151 seconds. Conversely, air pressure of 0.5 bar yields in maximum temperature of $662.0^{\circ} \mathrm{C}$ and longer combustion time, which is 843 seconds.
\end{abstract}

Keywords: stove, used oil, temperature, air pressure, time of combustion

\begin{abstract}
ABSTRAK
Oli bekas merupakan limbah, dimana belum terlalu optimal untuk di jadikan bahan bakar. Pada pembakaran oli bekas tekanan udara sangat berpengaruh untuk mencapai temperatur yang optimal. Hal ini berpengaruh pada tekanan udara yang masuk.. Di mana tekanan udara merupakan salah satu faktor yang mempengaruhi dan menentukan kerapatan udara selain daripada suhu. Metode Penelitian yang berkaitan dengan pengaruh tekanan udara terhadap temperatur pembakaran oli bekas pada kompor gas ini menggunakan metode eksperimen. Penelitian ini dapat di simpulkan bahwa tekanan udara berpengaruh pada temperatur pembakaran oli bekas. Pengaruh tekanan udara terhadap temperatur pembakaran yaitu apabila tekanan udara semakin tinggi maka temperatur pembakaran yang di hasilkan lebih maksimal dengan tekanan 2,5 bar mendapatkan $994,5^{\circ} \mathrm{C}$ dan pembakaran semakin cepat yaitu mencatatkan waktu 151 detik, sebaliknya tekanan semakin rendah maka temperatur pembakaran minimal dengan 0,5 bar mendapatkan temperatur $662,0^{\circ} \mathrm{C}$ dan memperoleh waktu pembakaran yang lebih lama yaitu sebesar 843 detik.
\end{abstract}

Kata Kunci: kompor, oli bekas, temperatur, tekanan udara, waktu pembakararan

\section{PENDAHULUAN}

Oli bekas merupakan limbah, di mana belum terlalu optimal untuk dijadikan bahan bakar. Oli bekas bisa didaur ulang dan biasanya digunakan untuk pelumas rantai motor. Penggunaan utama oli yaitu terdapat pada pelumas mesin. Umumnya oli terdiri dari $90 \%$ minyak dasar dan $10 \%$ zat tambahan. Berdasarkan jenis base oilnya minyak pelumas diklasifikasikan menjad 2, yaitu oli mineral, oli sintetis. Oli bekas terdapat nilai kalor. Nilai kalor adalah suatu angka yang menyatakan jumlah panas/kalori yang dihasilkan dari proses pembakaran sejumlah tertentu bahan bakar dengan udara/oksigen.

Pada pembakaran oli bekas tekanan udara sangat berpengaruh untuk mencapai temperatur yang optimal. Kompor oli bekas memiliki temperatur pembakaran tidak stabil. Hal ini memilki dampak yaitu suhu yang di hasilkan tidak maksimal. Nyala api yang di hasilkan cenderung perlahan redup dan suhu menurun. Dampak berikutnya yang ditimbulkan pada proses pembakaran, asap atau gas buang akan menyebabkan polusi. Nyala api yang tidak optimal serta konsistensi temperatur. Pada oli bekas temperatur akan mudah berubah. Oli 
bekas harus konstan terjaga temperaturnya agar dapat menghasilkan api sempurna. Hal ini berpengaruh pada tekanan udara yang masuk. Tekanan menggambarkan gaya per satuan luas pada suatu ketinggian tertentu. Di mana tekanan udara merupakan salah satu faktor yang mempengaruhi dan menentukan kerapatan udara selain daripada suhu. Apabila volume udara dan bahan bakar tidak sesuai api yang ditimbulkan biasanya akan mengeluarkan asap tebal. Hal ini terjadi efek dari bahan bakar oli bekas yang mempunyai tingkat viskositas oli mesin yang lebih tinggi tidak akan mampu melumasi komponen mesin. Oleh karenanya dapat mempengaruhi umur komponen.

Temperatur maksimum yang di hasilkan belum diketahui, sehingga dampaknya belum bisa di jadikan syarat api untuk meleburkan logam. Temperatur api pada pembakaran minyak oli bekas dapat dijadikan bahan bakar alternatif. Oli yang di gunakan termasuk ke dalam pembakaran dengan batas pencapaian temperatur tertentu. Perubahan nilai viskositas terhadap kenaikan suhu merupakan suatu hal yang penting untuk dipertimbangkan dalam berbagai jenis penerapan minyak pelumas. Kenaikan suhu berpengaruh dalam waktu proses pembakaran. Untuk mencapai temperatur optimal menggunakan perbandingan bahan bakar dan tekanan udara yang masuk, pencampuran bahan bakar dan tekanan udara, serta mulainya pembakaran pada kompor.

Berdasarkan permasalahan di atas maka peneliti tertarik untuk mengambil judul penelitian "Pengaruh Tekanan Udara Terhadap Temperatur Pembakaran Oli Bekas Pada Kompor”

\section{METODE}

Penelitian yang berkaitan dengan pengaruh tekanan udara terhadap temperatur pembakaran oli bekas pada kompor gas ini menggunakan metode eksperimen. Eksperimen sebagai sebuah atau sekumpulan percobaan yang dilakukan melalui perubahan-perubahan terencana terhadap variabel input suatu proses atau sistem sehingga dapat ditelusuri penyebab dan faktor-faktor sehingga membawa perubahan pada output sebagai respon dari eksperimen yang telah dilakukan. Menurut Puryadi dkk (2017) Metode eksperimen merupakan metode pemberian kesempatan kepada anak didik perorangan atau kelompok untuk dilatih melakukan suatu proses atau percobaan.

Alat yang digunakan dalam penelitian ini adalah kompor oli bekas sebagai alat utama dalam melaksanakan penelitian, kompresor untuk memvariasikan udara, termokopel atau temperatur sensor untuk mengukur suhu oli, alat ukur meteran untuk mengukur panjang nyala api, air pressure gauge untuk mengukur tekanan angin yang masuk, thermometer infrared untuk mengukur temperatur api.

Penelitian ini mengguanakan teknik analisis data. Analisis data adalah proses telaah dan pencarian makna dari data yang diperoleh untuk menemukan jawaban dari masalah penelitian.

Langkah awal menyiapkan kompor oli bekas yang sudah didesain dan dibuat sebelumnya, menyiapkan alat dan bahan guna penelitian, memasang termokopel pada kompor, memasang aliran selang kran untuk bahan bakar oli bekas, memasang aliran kompresor, menuangkan oli bekas pada selang yang sudah di pasang, menyalakan api dengan menggunakan dexlite untuk pemanasan start awal, setelah api menyala membuka kran penyalur udara dan kran oli, memvariasikan udara melalui pressure gauge di kompresor yaitu $1,1 \frac{1}{2}, 2,2^{1 / 2}$ dan 3 bar, mengambil data temperatur pada termokopel sesuai variasi tekanan pada pressure gauge di kompresor, mengendalikan debit bahan bakar oli yang masuk ke dalam kompor, dan mengamati bentuk nyala api pada kompor.

Setelah melakukan berbagai variasi tekanan, maka langkah selanjutnya ialah pengumpulan data. Data yang dikumpulkan adalah tekanan 1/2,1,11/2, 2 dan 21/2 bar beserta temperatur yang didapatkan setiap masingmasing variasi tekanan. 


\section{HASIL DAN PEMBAHASAN}

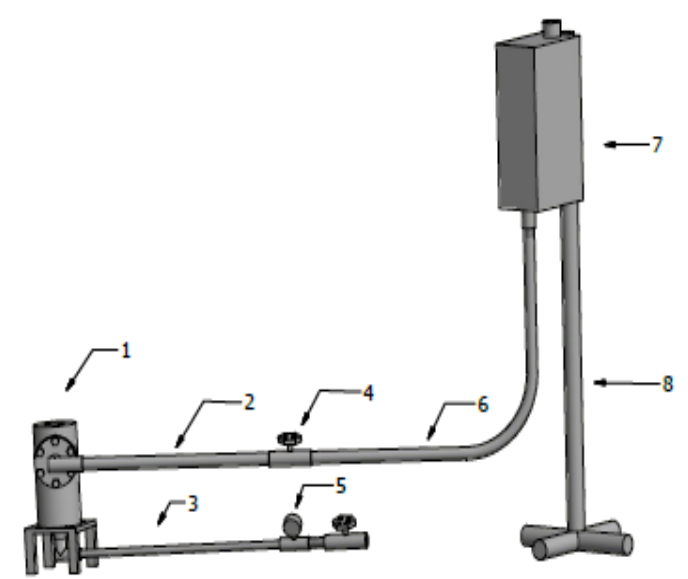

Gambar 1 Rancang Bangun Kompor

Tabel 1 Keterangan Gambar 3D Kompor (Burner)

\begin{tabular}{|c|c|c|c|c|}
\hline No. & Nama & $\mathrm{Jml}$ & Bahan & Keterangan \\
\hline 1 & $\begin{array}{l}\text { Badan } \\
\text { Kompor }\end{array}$ & 1 & $\begin{array}{l}\text { Pipa Besi } \\
\text { ST-44 }\end{array}$ & \multirow{8}{*}{$\begin{array}{l}\text { Mengukur } \\
\text { dari } 0-2,5 \\
\text { Bar }\end{array}$} \\
\hline 2 & $\begin{array}{l}\text { Selang Aliran } \\
\text { Oli }\end{array}$ & 1 & Pipa Besi & \\
\hline 3 & $\begin{array}{l}\text { Selang } \\
\text { Kompressor }\end{array}$ & 1 & Kuningan & \\
\hline 4 & Kran Putar & 2 & Kuningan & \\
\hline 5 & $\begin{array}{l}\text { Pressure } \\
\text { Gauge }\end{array}$ & 1 & & \\
\hline 6 & Selang Oli & 1 & Plastik & \\
\hline 7 & Tangki Oli & 1 & Plastik & \\
\hline 8 & $\begin{array}{l}\text { Tiang } \\
\text { Penyangga } \\
\text { Tangki }\end{array}$ & 1 & $\begin{array}{l}\text { Pipa Besi } \\
\text { Galvanis }\end{array}$ & \\
\hline
\end{tabular}

Kompor (burner) berbahan bakar oli bekas tersebut terbuat dari besi ST-44 yang memiliki diameter $11,5 \mathrm{~cm}$ dan tinggi kompor gas $29 \mathrm{~cm}$. Bentuk badan kompor memiliki dimensi yang besar, sehingga memiliki daya tampung yang besar pula. Karena di dalam badan kompor tersebut dapat menampung 2,8 liter oli bekas. Meskipun besar kompor tersebut dapat menghasilkan api berwarna jingga dengan temperatur maksimal $1154^{\circ} \mathrm{C}$. Kompor tersebut juga memiliki tekanan maksimal sebesar 3,5 bar. Namun tekanan tersebut menimbulkan suara yang bising dan api yang tidak stabil.

Temperatur ditujukan untuk menghitung suhu pembakaran oli bekas menggunakan variasi tekanan udara pada kompresor. Bahan bakar oli bekas di tentukan dengan volume 0,5 liter.

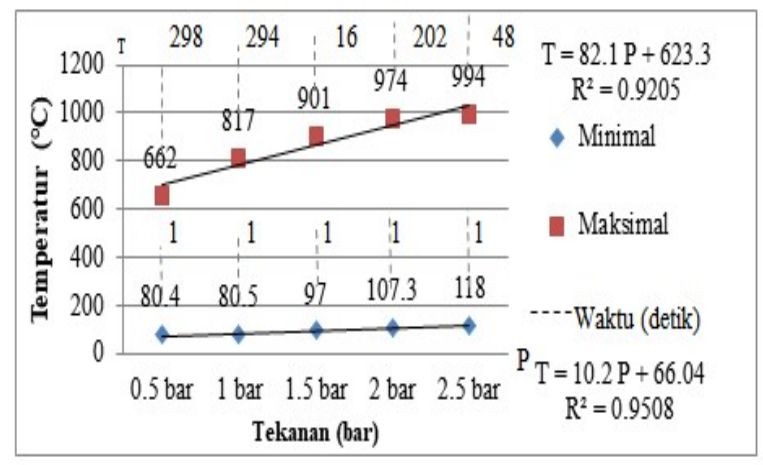

Gambar 2. Pengaruh tekanan udara terhadap temperatur pembakaran

Pada Gambar 2, y diartikan sebagai $\mathrm{T}$ (temperatur pembakaran) yang menjadi variabel terikat, $\mathrm{x}$ merupakan variabel bebas $\mathrm{P}$ (tekanan udara). Persamaan tersebut hanya berlaku mulai dari 0,5 sampai 2,5 bar. Pada gambar di atas garis setrip adalah waktu saat menghitung temperatur.

Langkah pertama memvariasikan tekanan yaitu 0,5, 1, 1,5, 2 dan 2,5 bar. Setiap variasi tekanan maka diambil contoh temperatur minimal dan maksimal. Selanjutnya diperoleh temperatur pembakaran dengan tekanan $0,5 \mathrm{bar}$ $\left(80.4^{\circ} \mathrm{C}-662.0^{\circ} \mathrm{C}\right), 1$ bar $\left(80.5^{\circ} \mathrm{C}-817.0^{\circ} \mathrm{C}\right.$ ), 1,5 bar $\left(97.0^{\circ} \mathrm{C}-901.0^{\circ} \mathrm{C}\right), 2$ bar $\left(107.3^{\circ} \mathrm{C}\right.$ - $\left.974.0^{\circ} \mathrm{C}\right)$ dan 2,5 bar $\left(118.0^{\circ} \mathrm{C}-994.5^{\circ} \mathrm{C}\right)$. Pada Gambar 1, y = bx + a, yaitu y diartikan sebagai $\mathrm{T}$ (temperatur pembakaran) yang menjadi variabel terikat, $\mathrm{x}$ merupakan variabel bebas yaitu $\mathrm{P}$ (tekanan udara). Batasan garis yang dihasilkan oleh tekanan udara mulai dari 0,5 sampai 2,5 bar. Apabila perhitungan kurang dari 0,5 dan lebih dari 2,5 maka persamaan garis ini tidak berlaku. Harga a sebagai konstanta dalam gambar tersebut diperoleh sebesar 623,3 maksimal dan 66,04 minimal. Harga b sebagai koefisien regresi yaitu 82,1 maksimal dan 10,2 minimal. Harga $\mathrm{R}^{2}$ sebagai koefisien determinasi mempunyai nilai antara 0 dan 1 dalam gambar di atas diperoleh sebesar 0,9500 minimal dan 0,9205 maksimal. Persamaan tersebut hanya berlaku mulai dari 0,5 sampai 
2,5 bar. Harga $\mathrm{R}^{2}$ merupakan sumbangan pengaruh tekanan udara $(\mathrm{P})$ terhadap temperatur pembakaran (T) sebesar 95\% untuk minimal dan 92,05\% maksimal. Jadi semakin tinggi nilai P, maka semakin rendah nilai (T). Nilai 5\% minimal dan 7,95\% maksimal merupakan faktor luar yang salah satunya yaitu tekanan atmosfer yang telah di buktikan pada persamaan garis Gambar 1.

Menggunakan variasi tekanan udara pada kompresor. Bahan bakar oli bekas di tentukan dengan volume 0,5 liter. Harga $\mathrm{D}=\frac{V}{t}$, maka diperoleh debit sebagai berikut 0,000593, 0,000722, 0,000778, 0,001683 dan 0,003311 liter/detik.

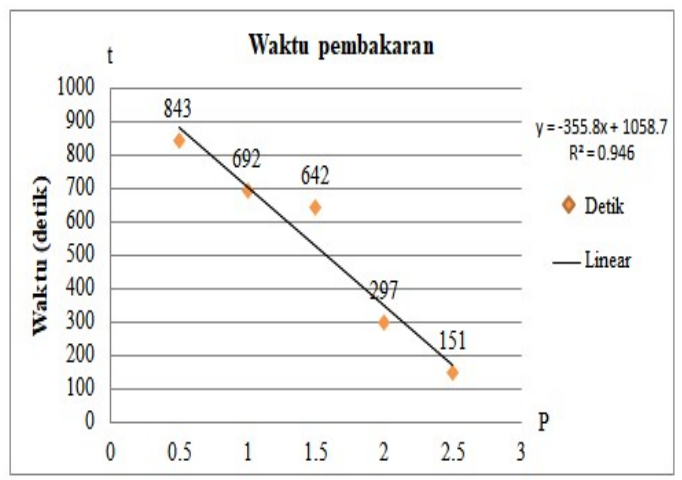

Gambar 3. Pengaruh tekanan terhadap waktu pembakaran

Gambar 3, y = bx + a, yaitu y diartikan sebagai t (waktu pembakaran) yang menjadi variabel terikat, $\mathrm{x}$ merupakan variabel bebas diartikan P (tekanan udara). Batasan garis yang di hasilkan oleh tekanan udara mulai dari 0,5 sampai 2,5 bar. Apabila perhitungan kurang dari 0,5 dan lebih dari 2,5 maka persamaan garis ini tidak berlaku. a sebagai konstanta dalam gambar tersebut diperoleh sebesar 1058,7. b sebagai koefisien regresi yaitu $-355,8 . \mathrm{R}^{2}$ sebagai koefisien.

Gambar di atas yaitu y diartikan sebagai t (waktu pembakaran) yang menjadi variabel terikat, $\mathrm{x}$ merupakan variabel bebas diartikan $\mathrm{P}$ (tekanan udara). Persamaan tersebut hanya berlaku mulai dari 0,5 sampai 2,5 bar.
Setelah tekanan ditentukan guna menghitung laju aliran bahan bakar oli, maka mendapatkan satuan waktu tiap variasi tekanan yang berbeda-beda yaitu tekanan 0,5 bar (843 detik), 1 bar (692 detik), 1,5 bar (642 detik), 2 bar (297 detik), 2,5 bar (151 detik). Setelah volume dan waktu ditentukan untuk mendapatkan debit bahan bakar dilakukan dengan rumus determinasi mempunyai nilai antara 0 dan 1 dalam gambar diatas diperoleh sebesar 0,946. Persamaan tersebut hanya berlaku mulai dari 0,5 sampai 2,5 bar. Harga $\mathrm{R}^{2}$ merupakan sumbangan pengaruh tekanan udara (P) terhadap waktu pembakaran (t) sebesar 94,6\%. Jadi semakin tinggi nilai $\mathrm{P}$, maka semakin rendah nilai (t). Nilai 5,4\% merupakan faktor luar yang salah satunya yaitu tekanan atmosfer yang telah di buktikan pada persamaan garis Gambar 4.

Pengaruh tekanan udara terhadap temperatur pembakaran yaitu apabila tekanan udara semakin tinggi maka temperatur pembakaran yang dihasilkan lebih maksimal dengan tekanan 2,5 bar mendapatkan $994,5^{\circ} \mathrm{C}$ dan pembakaran semakin cepat yaitu mencatatkan waktu 151 detik, Sebaliknya tekanan semakin rendah maka temperatur pembakaran minimal dengan 0,5 bar mendapatkan temperatur $662,0 \quad{ }^{\circ} \mathrm{C}$ dan memperoleh waktu pembakaran yang lebih lama yaitu sebesar 843 detik.

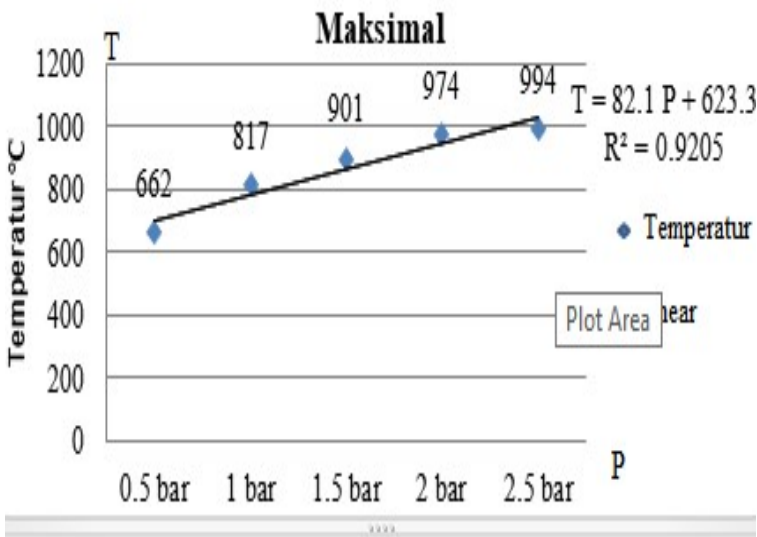

Gambar 4. Pengaruh tekanan udara terhadap temperatur maksimal 
Gambar 4, y diartikan sebagai $\mathrm{T}$ (temperatur pembakaran) yang menjadi variabel terikat, $\mathrm{x}$ merupakan variabel bebas diartikan $\mathrm{P}$ (tekanan udara). Batasan garis yang di hasilkan oleh tekanan udara mulai dari 0,5 sampai 2,5 bar.

Dari beberapa hasil penelitian di atas, di peroleh kesimpulan data pada Tabel 2.

Tabel 2. Kesimpulan Hasil Penelitian

\begin{tabular}{|c|c|c|c|c|c|}
\hline $\begin{array}{c}\text { No } \\
\text {. }\end{array}$ & $\begin{array}{l}\text { Vo } \\
\text { l } \\
\text { BB } \\
\text { (lt) }\end{array}$ & $\begin{array}{c}\text { Varia } \\
\text { si } \\
\text { Tek. } \\
\text { (bar) }\end{array}$ & $\begin{array}{l}\text { Temperat } \\
\text { ur } \\
\text { Maksimal } \\
\left({ }^{\circ} \mathrm{C}\right)\end{array}$ & $\begin{array}{c}\text { Debit } \\
\text { bahan } \\
\text { bakar } \\
\text { (liter/deti } \\
\text { k) }\end{array}$ & $\begin{array}{c}\text { Waktu } \\
\text { Pembakar } \\
\text { an (detik) }\end{array}$ \\
\hline 1 & $\begin{array}{c}0,5 \\
\text { lite } \\
r\end{array}$ & $\begin{array}{l}0,5 \\
\text { bar }\end{array}$ & $662.0^{\circ} \mathrm{C}$ & 0,000593 & 843 \\
\hline 2 & $\begin{array}{c}0,5 \\
\text { lite } \\
\mathrm{r}\end{array}$ & 1 bar & $817.0^{\circ} \mathrm{C}$ & 0,000722 & 692 \\
\hline 3 & $\begin{array}{c}0,5 \\
\text { lite } \\
\mathrm{r}\end{array}$ & $\begin{array}{l}1,5 \\
\text { bar }\end{array}$ & $901.0^{\circ} \mathrm{C}$ & 0,000778 & 642 \\
\hline 4 & $\begin{array}{c}0,5 \\
\text { lite } \\
r\end{array}$ & 2 bar & $974.0^{\circ} \mathrm{C}$ & 0,001683 & 297 \\
\hline 5 & $\begin{array}{c}0,5 \\
\text { lite } \\
\mathrm{r}\end{array}$ & $\begin{array}{l}2,5 \\
\text { bar }\end{array}$ & $994.0^{\circ} \mathrm{C}$ & 0,003311 & 151 \\
\hline
\end{tabular}

Setelah pembakaran oli bekas dilakukan variasi tekanan maka memperoleh temperatur paling tinggi, langkah pertama menentukan tekanan 0,5, 1, 1,5, 2 dan 2,5 bar. Dengan bahan bakar sebesar 0,5 liter mendapatkan temperatur maksimal sesuai variasi tekanan yaitu 0,5 bar (662.0 $\left.{ }^{\circ} \mathrm{C}\right), 1$ bar $\left(817.0^{\circ} \mathrm{C}\right), 1,5$ bar $\left(901.0^{\circ} \mathrm{C}\right), 2$ bar $\left(974.0^{\circ} \mathrm{C}\right)$ dan 2,5 bar $\left(994.0^{\circ} \mathrm{C}\right)$, dengan masing-masing mencatatankan waktu yaitu 843 detik, 692 detik, 642 detik, 297 detik dan 151 detik. Jadi temperatur tertinggi di peroleh pada tekanan 2,5 bar dengan waktu pembakaran 151 detik.

Gambar 4, y = bx + a, yaitu y diartikan sebagai $\mathrm{T}$ (temperatur pembakaran) yang menjadi variabel terikat, $\mathrm{x}$ merupakan variabel bebas diartikan $\mathrm{P}$ (tekanan udara). Batasan garis yang di hasilkan oleh tekanan udara mulai dari 0,5 sampai 2,5 bar. a sebagai konstanta dalam gambar tersebut diperoleh sebesar 623,3. b sebagai koefisien regresi yaitu 82,1. Harga $\mathrm{R}^{2}$ sebagai koefisien determinasi mempunyai nilai antara 0 dan 1 dalam gambar di atas diperoleh sebesar 0,9205 maksimal. Harga $\mathrm{R}^{2}$ merupakan sumbangan pengaruh tekanan udara (P) terhadap temperatur pembakaran $(\mathrm{T})$ sebesar 92,05\%. Jadi semakin tinggi nilai $\mathrm{P}$, maka semakin rendah nilai (T). Nilai 7,95\% merupakan faktor luar yang salah satunya yaitu tekanan atmosfer yang telah di buktikan pada persamaan garis Gambar 4.

\section{SIMPULAN}

Penelitian sudah selesai dilaksanakan maka memiliki kesimpulan sebagai berikut:

1. Kompor berbahan bakar oli bekas dapat divariasikan dengan tekanan udara pada kompresor. Apabila tekanan udara semakin tinggi yaitu 2,5 bar maka bahan bakar cepat habis mencatatkan 151 detik tapi memiliki keuntungan dengan pencapaian temperatur yang lebih tinggi sebesar $994^{\circ} \mathrm{C}$. Adapun sebaliknya dengan tekanan udara semakin rendah yaitu 0,5 bar maka bahan bakar lebih lama habis mencatatkan 843 detik tapi memiliki kelemahan dengan temperatur yang semakin rendah sebesar $662^{\circ} \mathrm{C}$. Sedangkan laju aliran dapat diketahui dengan menentukan volume bahan bakar $1 / 2$ liter dibagi dengan waktu tiap masingmasing tekanan udara. Tekanan udara terendah 0,5 bar mendapatkan waktu laju aliran sebesar 0,000593 liter/menit. Sedangkan tekanan udara tertinggi 2,5 bar mendapatkan waktu laju aliran sebesar 0,003311 liter/menit.

2. Kompor menggunakan oli bekas bisa menghasilkan temperatur minimal dan maksimal yang berbeda-beda sesuai dengan variasi tekanan udara. Kompor mendapatkan temperatur maksimal sebesar $994^{\circ} \mathrm{C}$ dengan tekanan udara 2,5 bar menggunakan kompresor. Selain temperatur maksimal kompor juga memiliki suhu terendah sebesar $80.4{ }^{\circ} \mathrm{C}$ dengan tekanan udara 0,5 bar.

Berikut saran yang perlu dilakukan yaitu memvariasikan tekanan udara lebih dari 2,5 bar untuk mendapatkan temperatur yang lebih 
tinggi. Membesarkan volume bahan bakar agar pembakaran dapat lebih lama di gunakan. Menentukan tekanan sesuai kebutuhan dalam pembakaran agar mendapatkan temperatur dan efisiensi bahan bakar yang maksimal.

\section{DAFTAR RUJUKAN}

Bambang, S., Hermawan, S., Ludfi, D., Hendi, B,. 2014. Pengaruh Peremaja Oli Bekas Dan Solar Terhadap Karakteristik Marshall Perkerasan Daur Ulang Dengan Asbuton. Jurnal Teknik Sipil. Universitas Brawijaya Malang

Dedy, A, S, P., Budiyono. Syafrudin. 2016. Analisis Kualitas Air Sungai Guna Menentukan Peruntukan Ditinjau Dari Aspek Lingkungan. Jurnal Lingkungan. Universitas Dipenogoro

Laode, A., Muhammad, H., Prinob, A. 2017. Pemanfaatan Minyak Oli Bekas sebagai Bahan Bakar Alternatif dengan Pencampuran Minyak Pirolisis. Jurnal.
Vol. 2, No.2.

Mamiek, M., Aloysius, L. 2018. Analisis Base Oil Hasil Proses Adsorpsi dan Pirolisis pada Oli Mesin Bekas. Jurnal Teknik Mesin. Politeknik Negeri Kupang

Nasim. 2014. Perbandingan Solar dengan Bahan Bakar yang Mirip Solar. Jurnal.

Puryadi, Bambang, S., Turjai, S. 2019. Penerapan Metode Eksperimen Untuk Meningkatkan Sikap Ilmiah Dan Prestasi Belajar Siswa (Studi Pada Mata Pelajaran Ipa Di Kelas V Sd Negeri Gugus Ii Taba Penanjung Bengkulu Tengah). Jurnal Ilmu Teknologi Pendidikan Universitas Bengkulu

Syarifah, Y., Amirul, A., Rosli, A. 2013. Emissions of Transeterification JatrophaPalm Blended Biodiesel. Journal. Procedia Engineering. 68: 265-270. 